\title{
An ADOxx Based Environment for Problem Based Learning in Manufacturing Systems Design
}

\author{
Ion Dan Mironescu ${ }^{1, *}$ \\ 1 " Lucian Blaga" University of Sibiu, Romania
}

\begin{abstract}
The Problem Based Learning (PBL) as student centred approach and learning-by-doing method is suited for the modern higher education. However, the first contact with the method can be overwhelming for the students, in the absence of prior domain knowledge. The preparation of the learning material can be time and resource consuming for the teacher. The goal of the research was the implementation of an environment that should enhance the learning experience for the student and reduce the implementation burden for the teacher. The environment is based on the ADOxx platform and allows the collaboration of the learner teams and the teacher-learner interaction on three levels. The Metamodeling level supports the development of the domain-specific language used in the modelling of the manufacturing system; this activity stimulates and directs the gathering and consolidation of domain-specific knowledge. The modelling level allows the development of alternative design solution using models of the factory components. The Simulation level allows the analysis of these variants. The environment supports the teacher in developing instructional scaffolding and uses cases to ease the learners the first time contact with PBL. The functionality of the environment is presented using the case of designing a flexible food production line.
\end{abstract}

\section{Introduction}

One of the factors that can drive the transformation of the actual manufacturing enterprises into Factories of the Future (FoF) are the digital skills [1]. The lack of such skills in the actual workforce has been identified as a delaying factor for the Factory 4.0 revolution [2]. Considering this, developing such skills in the future workforce is of primary importance for the manufacturing engineering education. As the overall higher education should shift to a student centred approach, the development of a curriculum for the acquirement of digital skills needed for the design, implementation and operation of the FoF is of high importance and value. Learning strategies that emphasize the personal practical experiences and use learning-by-doing methods are more effective in forming skills. Taking in account the specific digital skills that should be formed, the problem based learning (PBL) [3] approach has many advantages. The implementation of such a course requires more time and material resources and stresses more the trainers.

\footnotetext{
*Corresponding author: ion.mironescu@ulbsibiu.ro
} 
The goal of this research is the implementation of an environment that should enhance the learning experience of the student, reduce the burden of implementing for the teacher and improve the acquired knowledge.

\section{Requirements}

The requirement for the developed environment are:

- The environment should allow for the student the systematic and structured acquirement of the domain knowledge. We consider that the best method in a manner consequent to the learning method is the development of a Domain Specific Language. So the environment should support this development for both, students and teacher.

- The environment should allow the digital support for a Problem Based Learning oriented course. It should provide, for students and teacher:

o tool for the specification of the problems;

○ tools for the modelling of the proposed problem solution;

○ tools for simulation of the developed model. They will allow the evaluation of the models performance and consequently the selection of the best design.

- The environment should support the process of learning material elaboration for the teachers by providing templates for the problem formulation and presentation.

\section{Development}

The "Design and control of manufacturing processes in confectionary industry" course was chosen as a testbed for the developing of a computer assisted PBL laboratory. This is a $2^{\text {nd }}$ year course in the syllabus of the "Management of Food Modern Processing" Master. In the course, the students should acquire the knowledge and the skills needed for designing, implementing, organising and managing the daily operation of the manufacturing process of a confectionery product. The course should extends the basic knowledge and skills acquired in the bachelor studies with the modern methods for the product and process optimisation. The new approach will achieve these goals by asking the students to solve design and organisation problems for a cyber-physical system by using the digital tools. The laboratory hours are dedicated to the team-based problem solving and the course hours to analyse the solution, fix the acquired knowledge and direct the individual study for the preparation of the new practical hour.

The ADOxx environment [4], developed by the OMiLAB laboratory [5] of the University of Vienna, was used to implement the tools to support the practical activities. The environment allows the organisation of activity on three levels [6]:

- The Metamodeling level supports the development of the domain-specific language used for the modelling of the manufacturing system and of the graphical representation associated to the language entities; this activity stimulates and directs the gathering and consolidation of domain-specific knowledge and lays the foundation for the activity in the next levels;

- The Modelling level allows the development of the alternative design solution for the manufacturing line using the language and the graphical representation defined at the metamodeling level. At this level, the structural properties of the developed solution (connectivity, correctness, completeness) can be assessed by examining the resulted graphical representation of the model; 
- The Simulation level allows the analysis of the functionality of the design variants. Both qualitative (the line is functioning without blocking and manufactures the desired product) and quantitative analysis (the performance of the manufacturing line in terms of throughput, resource utilisations, efficiency, costs) can be performed.

\section{Test case}

The setting for all the problems that must be solved by the students is a confectionery factory that produces variable quantities from a larger assortment of products. The core of the process is the fabrication of some basic components: chocolate, caramel cream, nougat, jelly, marzipan that can be mixed in different products. The flexibility of the manufacturing process is provided through:

- multiple possibilities of forming and assembling the basic components:

$>$ layering different components;

$>$ putting a (semi) fluid filling in a solid shell;

$>$ covering a core.

- multiple option of packaging:

$>$ individual packaging - for each confectionery piece;

$>$ collective packaging - with or without individual packaging;

$>$ assortment packaging - with or without individual packaging.

This setting is discussed in the first course. The basic knowledge from the bachelor courses is remembered with the help of video footage presenting real enterprises, some of which the student visited during the practical work, and a 3D model of a virtual enterprise (to introduce not yet available equipment and machines).

\section{Learning process example}

A complete learning experience consists of three phases. In the first phase, which is supported by the metamodeling level of the environment, the modelling language for the description of a flexible confectionery production line is developed. The students were familiarized with the entity relation model from a database course in the bachelor curricula. To use this prior knowledge, the developed language was based on the entity relation model. The students discuss based on the enterprises visualised at the course and try to identify the interacting entities composing the system; the attributes of these entities are of interest for the understanding of the functioning and for the assessment of the system performance. The results of the discussion are recorded and are used later for the metamodeling.

In the practical application with the students, the following hierarchy of entities was identified:

- Flowing entities - representing the entities that are transported and consumed in the network:

$>$ Material - representing the raw material being transformed;

$>$ Energy - representing the driving source of the processing;

$>$ Information - representing the signals used for the control of the processing network.

- Processing entities - representing the nodes and the connexions between the nodes of the processing network: 
$>$ Machines - the processing nodes that consume energy and transform materials according to the incoming information. Each machine has a collection of input and output ports through which flowing entities of a specified type can be transported;

$>$ Fluxes - are connecting input and output ports of the same type allowing the transport of the flowing entities between processing nodes.

- Controlling entities - representing the entities that send and receive information to control the operation of processing entities:

$>$ Controllers - representing the cybernetic entities regulating the manufacturing process;

$>$ Operators - representing the humans commanding the manufacturing process.

The defined entities and relations are presented in figure 1.

First, the students were challenged to develop a graphical representation for the identified entities. This representation should allow the visualisation of the manufacturing line as a network of interconnected processing elements controlling the flow of material, energy and information steams. The graphical representation of the entities should include their actual two-dimensional outline, so that a rational floorplan design is also considered in the modelling phase.

The target group of the testbed case are students of food engineering with no hard computer skills. In this context the specification of the language and the graphical notation were used by the author to develop the components of the learning environment.

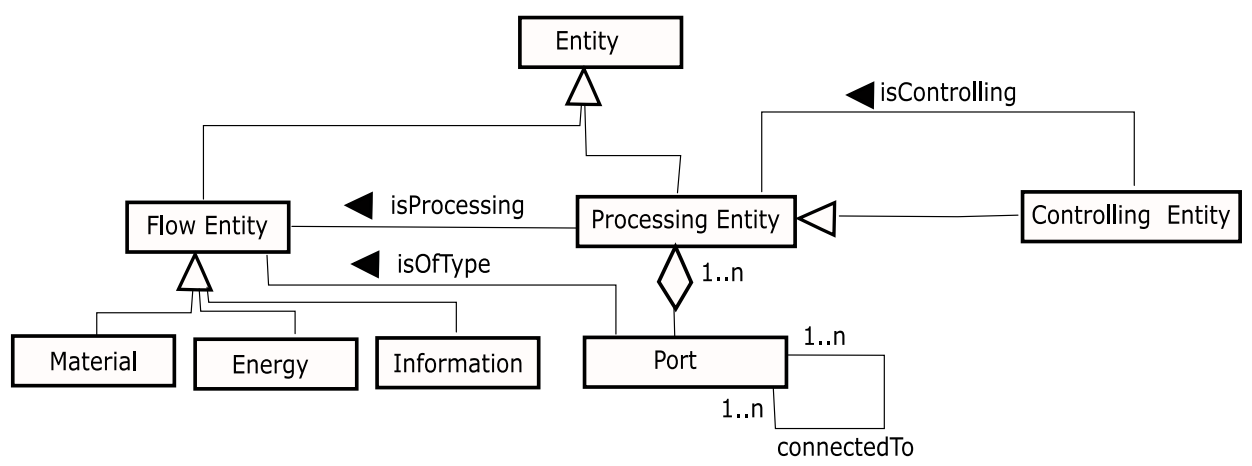

Fig. 1. Metamodel of the modelling language.

The author implemented the toolchain for the model simulation. The flow graph representing the completely connected model of the production line was mapped to a Petri Net using the approach described in [7] by representing the flow of material energy and information through the flow of token trough the places and transition. This Petri net is used for the simulation and analysis of the manufacturing line. The machines are represented in the Petri Net through structures that reacts to information tokens changing the way in which they transport the energy and material token. This simulates the effect of a command on the machine that changes its processing behaviour. The CPN tool [8] was used as an instrument for the simulation based on the familiarity of the student with this tool from a related master course. The CPN tool use an XML based format. The models are exported in XML format from ADOxx and transformed - using XSLT - in the corresponding CPN networks. The students will then use this models to assess trough simulation the performances (mostly the makespan) of the manufacturing lines they design.

In the second stage, the students grouped in teams try to solve in each session the problem of designing a flexible manufacturing line that can produce a given assortment of 
products. The problems are increasing in difficulty from very easy (producing one base component) to very complex (obtaining a mix of multicomponent products packaged in assortments). The students define the models of the machines using the modelling component of the environment and then graphically assemble them by connecting fluxes of the same type. Figure 2 presents the graphical representation of a line that can produce tricomponent composite snack size layered and covered confectionery product and package them in present type assortment boxes.

In the third phase - the optimisation phase, each team tries to find in each practical work session an efficient schedule for a given production mix. The students are simulating the models of the manufacturing line configuration they propose in CPN tools, are evaluating the performance of this configuration, and make then parameter and configuration adjustment to improve the schedule. The tasks are also increasing in difficulty from the simplest, which are still analytical tractable, to the more complex where heuristically and empiric/pragmatically strategies are the only solution - the scheduling problem is NP complete. The students are using their experience in designing manufacturing lines gained from the bachelor degree work to reduce the set of possible configuration combinations to a manageable set that they explore whit a trial and error approach.

By piecewise testing the envisaged educational strategy with the students, we developed a time schedule for a master course (Table 1). The course is Problem Based Learning oriented and uses the ADOxx based learning environment presented in this paper as support.

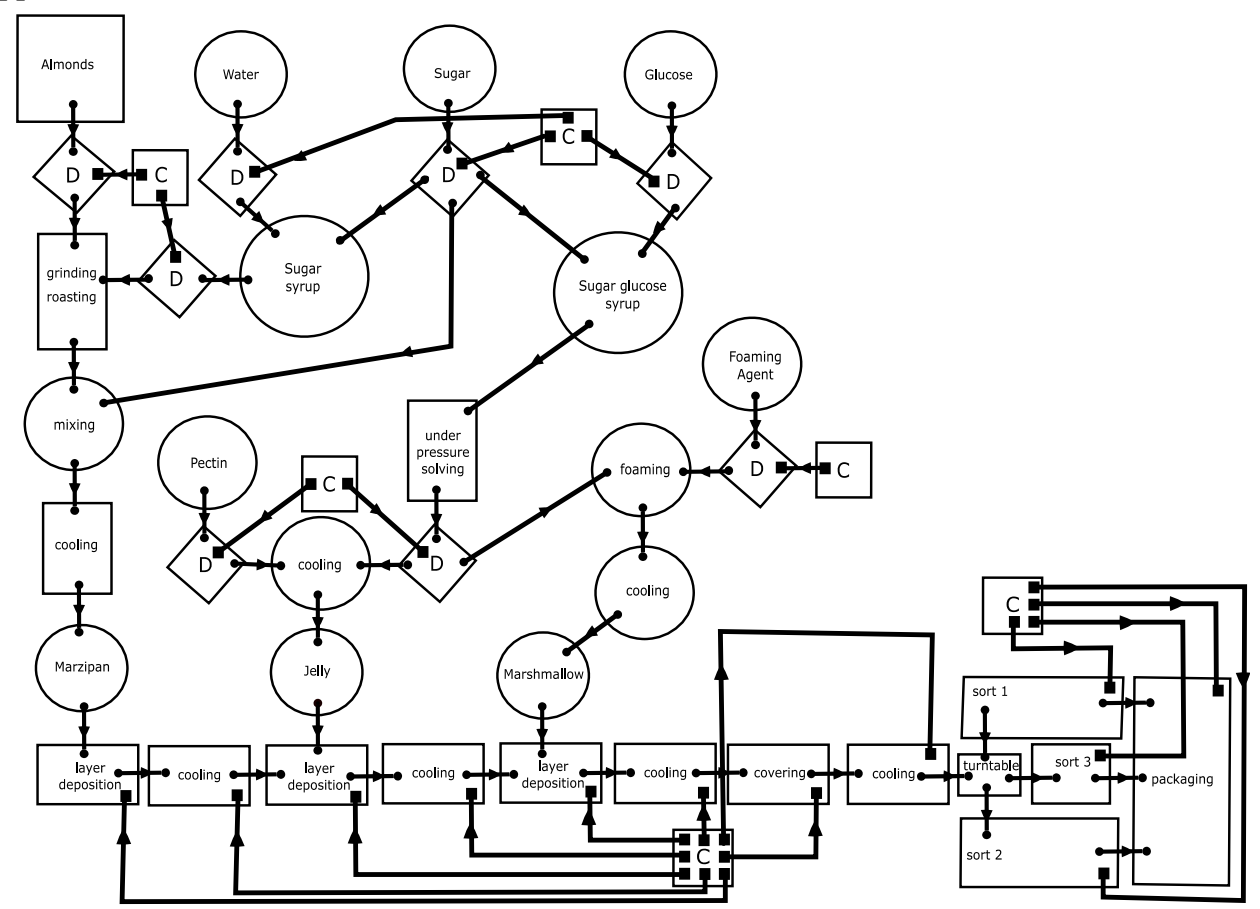

Fig. 2. Graphical representation for a line model. 
Table 1. Time schedule for the applied activity

\begin{tabular}{|c|c|}
\hline Week & Activity \\
\hline 1 & Discussion based development of the modelling language - group brainstorming. \\
\hline 2 & $\begin{array}{l}\text { Learning of the instrument in a learn think- pair-share adaptation - explore } \\
\text { individually the created environment and try to discover one useful aspect for } \\
\text { designing, pair with someone else to explore the discovered aspect, share to the } \\
\text { group. }\end{array}$ \\
\hline 3 & $\begin{array}{l}\text { The students are divided in teams that will compete in each training session to solve } \\
\text { a set of problems through modelling and simulation. The first problem is to generate } \\
\text { the model of a functioning confectionery plant by combining the given elements. } \\
\text { The plant should produce one mono component product without packaging. Each } \\
\text { team will have to produce one basis material for the mixed product (chocolate, } \\
\text { caramel, crisp jelly etc.). At the end, each team will present its solution and the } \\
\text { resulting model will be put in the common library for all teams to use in their next } \\
\text { design. }\end{array}$ \\
\hline 4 & $\begin{array}{l}\text { Each team integrates in his line the dividing and packaging unit so that an end } \\
\text { product can be delivered. }\end{array}$ \\
\hline 5 & Each team designs a line for the production of a two-component product. \\
\hline 6 & $\begin{array}{l}\text { Each team designs a line for the production of many component product, including } \\
\text { dividing and coating. Adjustment should be taken into account. }\end{array}$ \\
\hline 7 & $\begin{array}{l}\text { The teams uses all learned to design a plant that can be adapted to produce multiple } \\
\text { products and package them in different forms. }\end{array}$ \\
\hline 8 & $\begin{array}{l}\text { Each team works to optimise and adapt its line to produce a given quantity of a } \\
\text { single product in as short time as possible. The critical path will be identified. }\end{array}$ \\
\hline 9 & $\begin{array}{l}\text { Each team works to optimise and adapt its line to produce a given quantity of two } \\
\text { products in as short time as possible. The critical path will be identified. }\end{array}$ \\
\hline 10 & $\begin{array}{l}\text { Each team works to optimise and adapt its line to produce a given quantity of two } \\
\text { products in as short time as possible. The critical path will be identified. }\end{array}$ \\
\hline 11 & $\begin{array}{l}\text { Each team works to produce an assorted mix of product (in various packaging) in } \\
\text { the shortest time. }\end{array}$ \\
\hline 12 & Each team works to reduce the costs of its production line. \\
\hline 13 & $\begin{array}{l}\text { Each team works to cope with some of the resources (man, machines, materials) } \\
\text { becoming unavailable. }\end{array}$ \\
\hline 14 & $\begin{array}{l}\text { The teams will presents their final simulated enterprises discussing the solution they } \\
\text { found for the different problems. }\end{array}$ \\
\hline
\end{tabular}

\section{Discussion}

The models produced during the sessions with the master students were analysed by the author. The student also completed a final assessment of the knowledge acquired and a satisfaction survey. The produced model even for complex system were functional and qualitative correct representation of manufacturing lines. This shows that the developed platform helps the student to acquire the skills needed to generate models and digital twins of products and processes at a factory scale. The scores for the final assessment have shown that the use of these digital models has helped them to understand better the functioning of the manufacturing line and to predict, in some cases, the results of their decisions. They learned how to interact with the new smart objects that are controlling the digital factory work floor of the future and how to express their control strategies in an algorithmically way suited to be implemented with the help of such objects. 
The modelling approach is essential for the development of systems thinking. The PBL setting for design problems has stimulated the development of design thinking and problem solving skills. The students developed until the end of the practical session a working solution, which is a god starting point for further optimisation. By discovering the possibilities of harnessing the complexity of a flexible system, they identified possible new business models - for example, by producing efficient small batches of customised confectionary products for special occasion. This was mentioned in the satisfaction surveys.

This experience in a real situation proofs that the developed environment and the associated proposed educational strategies can be a valuable tool in forming essential skills for the transformation of the present manufacturing system in the Factory of the future.

\section{Conclusion and further work}

We succeeded in developing an environment that facilitate the implementation of pedagogic strategies aimed at the formation of digital skills in manufacturing engineering students. The developed environment eases the implementation of PBL courses by allowing the rapid development of graphical modelling and simulation tools for domain-specific modelling languages. Even if the focus of our approach is not on forming the metamodeling skills as it is in [9], the participation of the students to the development of the domainspecific languages deepens and structures the domain-specific knowledge acquired. It also give them the capacity to interact with specialists in metamodeling easing the integration in collectives that will design the architecture of future factories.

The further development will be to integrate teams of engineering student from computer science and mechatronics. The computer science students can develop the modelling and simulation tools for all the teams starting from the transcripts of the discussion for the modelling language definition. Together with their colleagues from mechatronic degrees, they can start from the models elaborated by the food engineering students and design the real cybertronic components (robots coupled trough IoT and coordinated by a hierarchy of AI and human command components). The process can be flexible organised by using a PBL approach on all teams in related courses, by forming interdisciplinary mixed teams or giving some of the work as starting point for research or graduation projects.

\section{Acknowledgements}

This work was partially developed under the ERASMUS+ KA2 project "THE FOFDESIGNER: DIGITAL DESIGN SKILLS FOR FACTORIES OF THE FUTURE”, financing contract no. 2018-2553 / 001-001, project number 601089-EPP-1-2018-1-ROEPPKA2-KA, web: http://www.digifof.eu.

\section{References}

1. L. Huertas, Digital Skills to Enable the Future of UK Advanced Manufacturing, https://www.linahuertas.co.uk/digital-skills-to-enable-the-future-of-uk-advanced-manufacturing/ (2017)

2. E. Mueller, XL. Chen, R. Riedel, "Challenges and Requirements for the Application of Industry 4.0: A Special Insight with the Usage of Cyber-Physical System". CJME. 30 (5): 1050-1057. doi:10.1007/s10033-017-0164 (2017)

3. W. Hung, "Theory to reality: A few issues in implementing problem-based learning". Educational Technology Research and Development. 59 (4): 529-552. doi:10.1007/s11423-0119198-1 
4. H. Kuehn, The ADOxx Metamodeling Platform. In Workshop on Methods as Plug-Ins for Meta Modeling, Klagenfurt, Austria. http://www.openmodel.at/c/documentlibrary/ getfile?uuid=7516b7c5-a525-4d92-929e-6c11e5da9d39\&groupId=10122 (2010)

5. D Bork, RA Buchman, D Karagiannis, M Lee, ET Miron. An Open Platform for Modeling Method Conceptualization: The OMiLAB Digital Ecosystem, Communications of the Association for Information Systems, forthcoming, http://eprints.cs.univie.ac.at/5462/1/CAISOMiLAB-final-withFront.pdf (2019)

6. D.Karagiannis, , H. C Mayr., J. Mylopoulos. Domain-specific conceptual modeling. Springer International Publishing (2016)

7. D. Mosteller, L. Cabac, M. Haustermann Integrating Petri Net Semantics in a Model-Driven Approach: The Renew Meta-Modeling and Transformation Framework. In: M. Koutny, J. Desel, J. Kleijn (eds) Transactions on Petri Nets and Other Models of Concurrency XI. Lecture Notes in Computer Science, vol 9930. Springer, Berlin, Heidelberg (2016)

8. K. Jensen and L.M. Kristensen. Coloured Petri Nets - Modeling and Validation of Concurrent Systems. Springer-Verlag Berlin (2009)

9. D. Bork. "A Framework for Teaching Conceptual Modeling and Metamodeling Based on Bloom's Revised Taxonomy of Educational Objectives." 52nd Annual Hawai'i International Conference on System Sciences (HICSS-52), pp. 7701-7710 (2019) 